\title{
Radially Branched Deployment for More Efficient Cell Transplantation at the Scale of the Human Brain
}

\author{
Matthew T. Silvestrini ${ }^{a}$ Dali Yin ${ }^{a}$ Valerie G. Coppes ${ }^{a, d}$ Preeti Mann ${ }^{a} d$ \\ Alastair J. Martin ${ }^{c}$ Paul S. Larson ${ }^{a}$ Philip A. Starr ${ }^{a}$ Nalin Gupta ${ }^{a}$ \\ S. Scott Panter ${ }^{a, d}$ Tejal A. Desai ${ }^{b}$ Daniel A. Lima, d, e
}

Departments of a Neurological Surgery, ${ }^{b}$ Department of Bioengineering and Therapeutic Sciences, and ${ }^{\mathrm{C}}$ Radiology, University of California San Francisco, ${ }^{d}$ Department of Surgery, San Francisco Veterans Affairs Medical Center, and eEli and Edythe Broad Center of Regeneration Medicine and Stem Cell Research at UCSF, San Francisco, Calif., USA

\section{Key Words}

Radially branched deployment $\cdot$ Neural stem cell $\cdot$ Cell transplantation $\cdot$ Stereotactic surgery

\begin{abstract}
Background: In preclinical studies, cell transplantation into the brain has shown great promise for the treatment of a wide range of neurological diseases. However, the use of a straight cannula and syringe for cell delivery to the human brain does not approximate cell distribution achieved in animal studies. This technical deficiency may limit the successful clinical translation of cell transplantation. Objective: To develop a stereotactic device that effectively distributes viable cells to the human brain. Our primary aims were to (1) minimize the number of transcortical penetrations required for transplantation, (2) reduce variability in cell dosing and (3) increase cell survival. Methods: We developed a modular cannula system capable of radially branched deployment (RBD) of a cell delivery catheter at variable angles from the longitudinal device axis. We also developed an integrated catheter-plunger system, eliminating the need for a separate syringe delivery mechanism. The RBD prototype was evaluated in vitro and in vivo with subcortical injections into the
\end{abstract}

swine brain. Performance was compared to a 20G straight cannula with dual side ports, a device used in current clinical trials. Results: RBD enabled therapeutic delivery in a precise 'tree-like' pattern branched from a single initial trajectory, thereby facilitating delivery to a volumetrically large target region. RBD could transplant materials in a radial pattern up to $2.0 \mathrm{~cm}$ from the initial penetration tract. The novel integrated catheter-plunger system facilitated manual delivery of small and precise volumes of injection $(1.36 \pm 0.13 \mu \mathrm{l}$ per $\mathrm{cm}$ of plunger travel). Both dilute and highly concentrated neural precursor cell populations tolerated transit through the device with high viability and unaffected developmental potential. While reflux of infusate along the penetration tract was problematic with the use of the $20 \mathrm{G}$ cannula, RBD was resistant to this source of cell dose variability in agarose. RBD enabled radial injections to the swine brain when used with a modern clinical stereotactic system. Conclusions: By increasing the total delivery volume through a single transcortical penetration in agarose models, RBD strategy may provide a new approach for cell transplantation to the human brain. Incorporation of RBD or selected aspects of its design into future clinical trials may increase the likelihood of successful translation of cell-based therapy to the human patient.

Copyright @ 2013 S. Karger AG, Basel

\section{KARGER}

Fax +41613061234

E-Mail karger@karger.ch

www.karger.com (c) 2013 S. Karger AG, Basel

$1011-6125 / 13 / 0912-0092 \$ 38.00 / 0$

Accessible online at:

www.karger.com/sfn
Daniel A. Lim, MD, PhD

Department of Neurological Surgery, University of California

San Francisco, Ray and Dagmar Dolby Regeneration Medicine Building

35 Medical Center Way, RMB 1037, San Francisco, CA 94143 (USA)

E-Mail LimD@neurosurg.ucsf.edu 


\section{Introduction}

Cell transplantation to the brain significantly improves neu rological function in animal models of a wide variety of neurological disorders [1-4]. These preclinical studies have been translated into clinical trials for a multitude of conditions including Parkinson's disease (PD) [5-7], Huntington's disease [8-12] and stroke [1315]. However, human patient studies have produced mixed therapeutic results. Such variable patient outcomes - most clearly noted in double-blind, sham surgery, controlled transplantation trials for PD $[5,6]-$ have been partly attributed to an inability to properly distribute the cells to the target region $[16,17]$. There has been relatively little development of surgical tools and techniques for the delivery of cells to the human brain [18-25]. If unresolved, deficiencies in surgical delivery may result in the failure of human cell transplantation trials despite the validity of the underlying biological mechanisms.

To date, cells have been delivered to the human brain with a stereotactically inserted straight cannula $[5,6,21$, $26,27]$. While effective for small animal experimental models, straight cannula transplantation strategies present significant challenges when scaled up for human therapy. The human brain is $800-2,300$ times larger than that of rodents used for preclinical research. With a straight cannula, cell delivery to the larger target volumes of human brain requires several independent brain penetrations $[5,6,21,26,27]$. Some patients with $\mathrm{PD}$ have received a total of 16 separate penetrations for transplantation to the putamen [26]. Every transcortical brain penetration injures normal brain tissue and threatens hemorrhagic stroke.

In another approach to translational scale-up, very large numbers of cells were delivered to a single location or along a short segment of the cannula tract [28]. Unfortunately, the implantation of a large mass of cells within a confined location can severely impair graft viability, resulting in necrosis at the center of the transplant [29]. Furthermore, larger injection volumes worsen the reflux of infused materials along the penetration tract [30, 31], making cell dosing unpredictable in terms of numbers as well as final graft location.

In most clinical trials, a syringe is used to deliver cells through the inserted cannula. Unless the syringe is kept in constant motion, the cells naturally sediment to the most dependent location, usually the end attached to the cannula [32]. Thus, the first partial injection volume from a syringe may contain far more cells than those dis-

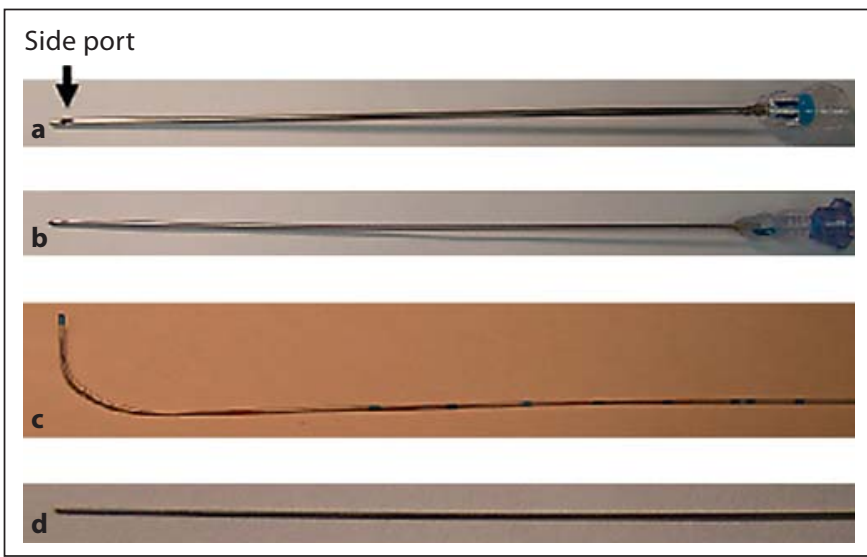

Fig. 1. Components of the RBD prototype. Outer guide tube (a), inner guide tube (b), cell delivery catheter (c) and plunger wire (d). These separated RBD components assemble in a nested manner.

pensed later, further contributing to unpredictable variability of cell dosing.

A more ideal device and neurosurgical strategy would enable the distribution of relatively small cellular deposits to larger $\left(>3 \mathrm{~cm}^{3}\right)$ target locations through a single initial brain penetration. Here, we report the design and function of a device capable of catheter deployment at radial trajectories 'branched' from essentially any rotational angle and depth along a single transcortical penetration tract. For this radially branched deployment (RBD) prototype, we innovated an integrated catheterplunger system that facilitated accurate and precise manual delivery of small infusate volumes, eliminating the need for a separate syringe. The use of RBD with a commercially available stereotactic platform for delivery into the brain of swine supports the feasibility of efficiently 'arborizing' larger human brain targets, such as the putamen, with cell therapy.

\section{Materials and Methods}

Device Design

The RBD prototype consists of an outer guide tube (fig. 1a), inner guide tube (fig. 1b), cell delivery catheter (fig. 1c) and plunger wire (fig. 1d) that assemble in a nested manner. In the prototype described here, the outer and inner guide tubes are rigid and made of stainless steel. Nonparamagnetic materials including polyether ether ketone and nylon-12 can be used for these components, which would allow the use of RBD in the high-field magnetic environment associated with intraoperative MRI; another prototype employing these materials is in development. The outer guide tube (outer diameter, OD: $2.4 \mathrm{~mm}$; inner diameter, ID: 1.8 


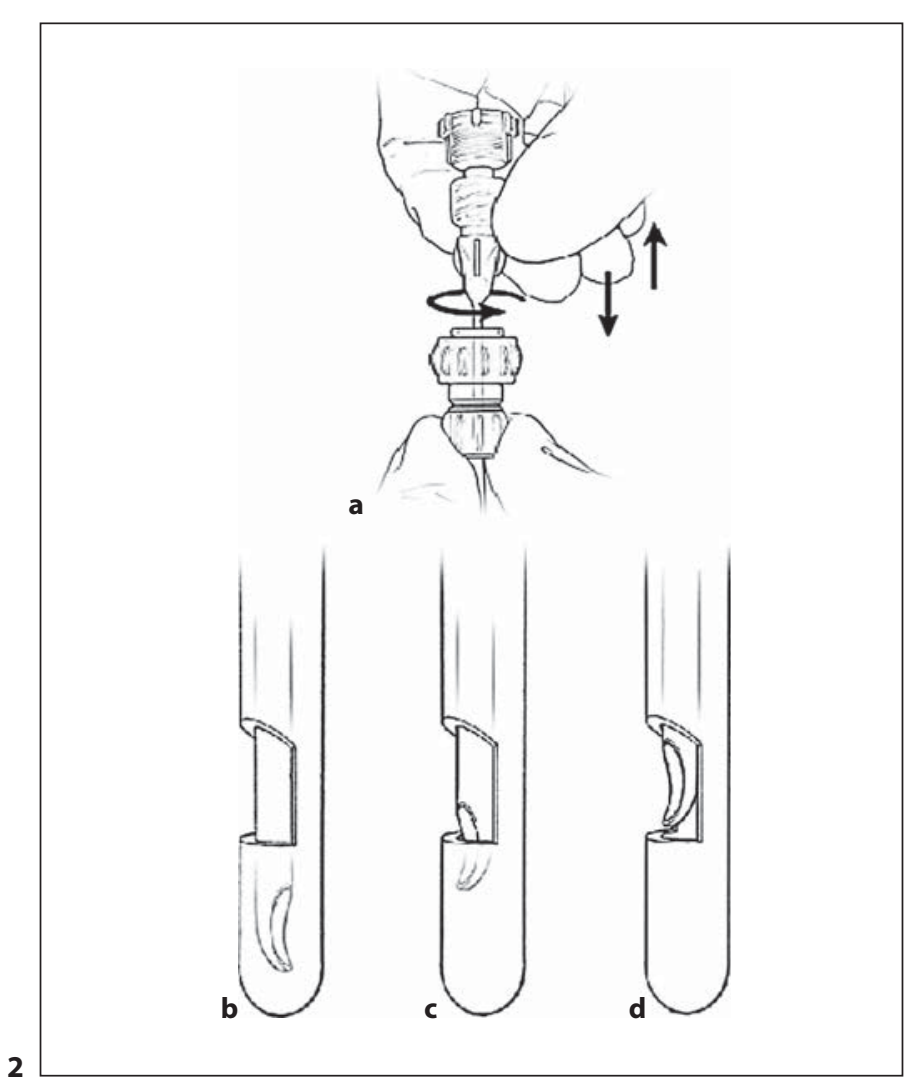

Fig. 2. Open and closed configurations of the outer guide tube side port. The side port can be opened (d) or closed (b) by the user through rotation (curved arrow) and linear translation (straight arrows, up or down) of the inner guide tube (c) via manipulation of the proximal inner guide tube controls (a).

Fig. 3. Control and safety elements of the RBD prototype. The $\mathrm{RBD}$ prototype is shown here integrated with the Clearpoint SmartFrame. A = Plunger lock: this torquer at the catheter proximal end controls movement of the plunger wire; $\mathrm{B}=$ catheter lock: this Touhy-Borst adaptor provides a gas-tight seal at the most proximal end and must be opened to allow linear translation of the catheter within the inner guide tube; $\mathrm{C}=$ side port lock: with this Touhy-Borst adaptor, the RBD prototype can be locked in either the open or closed configurations; $\mathrm{D}=$ depth stop: this stop collar, affixed to the SmartFrame, controls the depth and rotation of the RBD outer guide tube.

$\mathrm{mm}$; fig. 1a) has a side port $4 \mathrm{~mm}$ from the distal end, and this can be opened or closed by the user through translation and rotation of the inner guide tube (fig. 2). The RBD can be locked in either the open or closed configurations by engaging the Touhy-Borst adaptor at the device proximal end (side port lock; fig. 3, point C). The inner guide tube (OD: $1.65 \mathrm{~mm}$, ID: $1.19 \mathrm{~mm}$, fig. $1 \mathrm{~b}$ ) has a deflected tip (radius of curvature $=1 \mathrm{~cm}$ ), and when the RBD device is in the open configuration, the deflected tip lines up with the side port of the outer guide tube. Accu-Tube Corporation (Englewood, Colo., USA) carried out the operations necessary to make the deflected tip of the inner guide tube.



A flexible cell delivery catheter made of nylon-12 (OD: 1mm, ID: $0.4 \mathrm{~mm}$, fig. 1c) translates linearly within the inner guide tube. The RBD prototype incorporates a safety mechanism for catheter deployment: a second Touhy-Borst adaptor, which provides a gastight seal at the most proximal end (catheter lock; fig. 3, point B), must be opened by the user to allow translation of the catheter within the inner guide tube, preventing inadvertent catheter deployment. Furthermore, a simple depth stop (fig. 3, point D) on the cell delivery catheter prevents cannula insertion beyond the intended radial distance. 
To create cell delivery catheters with a curved distal end, we used a heat set procedure. A metal rod mandrel was inserted into the inner lumen of the catheter except for the last $1.5 \mathrm{~cm}$ from the distal end. This distal portion was then fixated to the desired radius of curvature. With a lab oven (RF1330FM; VWR, Batavia, Ill., USA), the nylon-12 catheter was heated to the glass transition temperature $\left(170^{\circ} \mathrm{F}\right)$ for $15 \mathrm{~min}$.

The lumen of the cell delivery catheter is fitted with a Ti6Al4V (grade 5 titanium) wire (OD: $0.4 \mathrm{~mm}$ ) that serves as a plunger (fig. 1d). The close fit between the walls of the catheter and the plunger wire provides a nearly gas-tight seal to allow both aspiration and dispensing of fluids. For safety, a torquer (plunger lock; fig. 3, point A) at the catheter proximal end prevents movement of the plunger wire. To allow translational movement of the plunger wire, the user must open this plunger lock. Of note, the catheter can be fixed at any deployed distance by closing the catheter lock while still allowing the user to manipulate the plunger wire by opening the plunger lock. Thus, advancement of the plunger wire does not result in movement of the catheter.

\section{Assessment of Catheter Deployment}

A ClearPoint system SmartFrame (MRI Interventions, Irvine, Calif., USA) was used to insert the RBD prototype $7 \mathrm{~cm}$ below the surface of a $0.4 \%$ agarose gel (Invitrogen; Life Technologies, Grand Island, N.Y., USA) cast within an acrylic box. This concentration of agarose mimics the modulus (stiffness) of brain tissue [33]. After insertion, the side port was opened, and the catheter was deployed $20 \mathrm{~mm}$. This fully deployed position was digitally imaged with a tripod-mounted SLR digital camera (D7000; Nikon, Tokyo, Japan). The catheter was then fully retracted back into the guide tube assembly. This process of catheter deployment and retraction was repeated 24 times over the course of $60 \mathrm{~min}$, and the final location of each catheter deployment was digitally captured. Image analysis with ImageJ (rsbweb.nih.gov/ij/, National Institutes of Health), was used to determine the standard deviation of error of the deployed catheter position. To visualize the path of catheter deployment, digital images were captured every $3 \mathrm{~mm}$, and images of these intermediate deployments were overlaid with the image of a fully deployed catheter (Adobe Photoshop; Adobe Systems, San Jose, Calif., USA).

\section{Evaluation of Volumetric Precision of the Catheter-Plunger}

System

A catheter, marked every $1 \mathrm{~cm}$ from the distal end, was backfilled with distilled water to the $15-\mathrm{cm}$ mark. The plunger wire was then advanced to each adjacent centimeter marking. The amount of water dispensed with each centimeter of plunger wire translational movement was determined by measuring the mass of the dispensed fluid on a precision analytic balance (AB54-S; Mettler Toledo, Columbus, Ohio, USA).

\section{Analysis of Cell Viability and Developmental Potential}

Mouse subventricular zone neural precursor cells (NPCs), prepared with cell culture methods as previously described [34, 35], were used for these studies. Briefly, the subventricular zone region was dissected from coronal brain sections, dissociated with $0.25 \%$ trypsin (Invitrogen) and cultured in N5 medium, which consists of DMEM/F12 with Glutamax, $5 \%$ fetal calf serum, $1 \% \mathrm{~N} 2$ supplement, bovine pituitary extract (35 $\mu \mathrm{g} / \mathrm{ml})$, epidermal growth factor $(20 \mathrm{ng} / \mathrm{ml})$, fibroblast growth factor $(20 \mathrm{ng} / \mathrm{ml})$
Table 1. Cell viability through the RBD system and $20 \mathrm{G}$ cannulasyringe system as assessed by flow cytometry

\begin{tabular}{ccl}
\hline Trial & $\begin{array}{l}\text { Cell density } \\
\text { cells/ml }\end{array}$ & $\begin{array}{l}\text { Alive cells } \\
\%\end{array}$ \\
\hline Viability of cells from RBD prototype & \\
1 & $8 \times 10^{7}$ & 99.6 \\
2 & $4 \times 10^{7}$ & 99.7 \\
3 & $2 \times 10^{7}$ & 99.4 \\
4 & $1 \times 10^{7}$ & 99.4 \\
Viability of cells from 20 G cannula & \\
1 & $8 \times 10^{7}$ & 99.6 \\
2 & $4 \times 10^{7}$ & 99.6 \\
3 & $2 \times 10^{7}$ & 99.9 \\
4 & $1 \times 10^{7}$ & 99.7 \\
\hline
\end{tabular}

and antibiotics/antimycotics (media and supplements from Invitrogen). The RBD catheter was backfilled with $50 \mu \mathrm{l}$ of each cell suspension and dispensed into a polystyrene test tube at a rate of $5 \mu \mathrm{l} / \mathrm{min}$. This procedure was performed for each of the four dilutions made (see table 1). Dead cells were stained with Sytox Red (Invitrogen) and quantified via flow cytometry (LSR II; BD Biosciences, San Jose, Calif., USA).

To assess the developmental potential of NPCs after transit through the RBD catheter, a $500-\mu$ l suspension of NPCs $\left(5 \times 10^{6}\right.$ cells $/ \mathrm{ml}$ ) in N5 was dispensed at $50 \mu \mathrm{l} / \mathrm{min}$, then subsequently cultured for 2 days in N5, differentiated in N6 medium (DMEM/ F12 with Glutamax, 1\% N2 supplement, bovine pituitary extract $35 \mu \mathrm{g} / \mathrm{ml}$, antibiotics/antimycotics) for 4 days, then fixed and analyzed with immunocytochemistry using techniques as previously described $[34,35]$. Primary antibodies: rabbit anti-GFAP (1:500 dilution; Dakocytomation, Carpinteria, Calif., USA), mouse antiO4 (1:100 dilution; Chemicon, Temecula, Calif., USA), and mouse anti-Tuj1 (1:500 dilution; Covance, Princeton, N.J., USA).

\section{Measurement of Reflux}

For reflux testing, both the RBD catheter and the $20 \mathrm{G}$ straight cannula were deployed $7 \mathrm{~cm}$ below the surface of $0.4 \%$ agarose gels cast within an acrylic box. For the RBD prototype, a ClearPoint system SmartFrame (MRI Interventions) was used as the delivery platform. The $20 \mathrm{G}$ straight cannula system was fixated to a ring stand with a utility clamp. For testing with Allura Red AC dye, 10 $\mu \mathrm{l}$ was dispensed at $2 \mu \mathrm{l} / \mathrm{min}$ through plunger wire advancement for RBD or screw-driven advancement of a P100 micropipet (Rainin Instrument LLC, Woburn, Mass., USA) attached to the 20G straight cannula.

Reflux of NPC suspensions was evaluated by determining both the volume and number of cells that refluxed to the gel surface. For both the RBD prototype and the 20G cannula, $100 \mu$ l of NPCs $(2.0$ $\times 10^{6} \mathrm{cell} / \mathrm{s} / \mathrm{ml}$ ) were delivered. Using the RBD prototype, five 100 $\mu \mathrm{l}$ deposits, each infused at approximately10 $\mu \mathrm{l}$ per min, were placed in a radial pattern at a single depth. The $20 \mathrm{G}$ cannula was fitted with a 1-ml syringe, and the NPC cells were injected over the course of $50 \mathrm{~min}$ (to approximate a delivery rate of $10 \mu \mathrm{l}$ per min). After delivery, we carefully withdrew the RBD prototype or the $20 \mathrm{G}$ cannula system from the gel, waited $30 \mathrm{~min}$, and then collected the material that had refluxed to the gel surface. 
Surgical Testing of RBD and Brain Histology

Three immature Yorkshire swine (weight, 20-30 kg each) were premedicated with ketamine $(20 \mathrm{mg} / \mathrm{kg})$, xylazine $(2 \mathrm{mg} / \mathrm{kg})$ and glycopyrrolate $(0.01 \mathrm{mg} / \mathrm{kg})$. They were intubated and ventilated with $1-4 \%$ isoflurane. A midline scalp skin incision was made, and a high-speed neurosurgical drill with a perforator bit (AcraCut, Acton, Mass., USA) was used to create bilateral burr holes centered at $11 \mathrm{~mm}$ lateral and $16 \mathrm{~mm}$ anterior to the bregma. After opening the dura with standard techniques, a ClearPoint system SmartFrame was mounted over a single burr hole. A trajectory perpendicular to the skull surface was used, and the RBD side port was inserted $20 \mathrm{~mm}$ below the cortical surface. In animal one and two, the catheter was deployed along three $20-\mathrm{mm}$ radial trajectories (anterior, posterior, lateral) in both the left and right hemispheres. In animal three, RBD was used for a single radial trajectory (lateral) in the right hemisphere; in the left hemisphere, the $20 \mathrm{G}$ straight cannula was inserted into the brain approximately $20 \mathrm{~mm}$ below the cortical surface through a modified ClearPoint SmartFrame. For each catheter or straight cannula insertion, $150 \mu \mathrm{l}$ of fluorescent microspheres (8-10 $\mu \mathrm{m}$ diameter, FITC-conjugated; Bangs Laboratories, Fishers, Ind., USA) suspended at a concentration of $2.65 \mathrm{mg} / \mathrm{ml}$ in sterile water was injected over 3-5 min. After injection, the catheter or cannula was left in place for 2-3 min before repositioning or removal. At the end of the procedure, with the animal still under anesthesia, a bilateral craniectomy was performed, and the brain was removed. It was then cut into $6-\mathrm{mm}$ slabs, placed in $4 \%$ paraformaldehyde for $24 \mathrm{~h}$ at $7^{\circ} \mathrm{C}$, then equilibrated in $20 \%$ sucrose in phosphate buffered saline for $48 \mathrm{~h}$ at $7^{\circ} \mathrm{C}$. Each $6-\mathrm{mm}$ slab was embedded on a freezing-sliding microtome stage at $-18^{\circ} \mathrm{C}$ and cut into $100-\mu \mathrm{m}$ sections. Selected sections were washed in phosphate buffered saline and mounted onto glass slides with Thermogel (Thermo Scientific, Waltham, Mass., USA). Brain sections were imaged with both a Leica MZ75 dissection microscope and a DMI400B epifluorescent microscope (Leica Microsystems, Wetzlar, Germany).

\section{Results}

RBD Enables Multiple, Precise Catheter Placements within a Volumetrically Large Region through a Single Transcortical Penetration in Agar

The RBD prototype described in this report utilizes the proven and accurate platform of current stereotactic systems. A cylindrical cannula introduced by any modern stereotactic frame can be precisely rotated around the axis of the initial trajectory and retracted to more superficial brain regions without incurring additional neural damage. Thus, the ability to deploy a cell delivery catheter at multiple radii and depths would allow one to efficiently 'arborize' the brain target region with transplanted cells.

In its 'closed' configuration, the RBD prototype resembles a standard stereotactic biopsy cannula in length, outer diameter and outward appearance. To enable the delivery of cells along a radial trajectory at angles up to perpendicular to the primary cannula axis, the RBD prototype incorporates several design aspects. At the distal end of the outer guide tube, the RBD prototype has a side port that - when opened with controls at the proximal end - exposes the deflected bore tip of the inner guide tube. This inner guide tube encloses a semiflexible catheter with a preset bend at the distal end. This catheter exists in a straightened state when it is entirely contained by the inner guide tube. When the catheter is advanced at the proximal end, it emerges from the distal side port along a radially oriented path (fig. $4 a, b$ ).

Through the combined action of the deflected bore tip and the preset right-angle catheter bend, the path of catheter deployment was precisely determined. Figure $4 \mathrm{c}-\mathrm{g}$ shows the final deployed path overlaid with the stepwise actual path of the catheter during deployment. This final location of the deployed catheter tip was highly precise (standard deviation $= \pm 0.27 \mathrm{~mm}$ vertical dimension, \pm $0.11 \mathrm{~mm}$ radial dimension, $\mathrm{n}=25$ trials). By varying catheter advancement at the proximal end, the user can reliably deploy the catheter to planned target locations radial to the main trajectory axis. With the shown catheter (radius of curvature of $0.5 \mathrm{~cm}$ located $1.5 \mathrm{~cm}$ from the distal end), the maximum radial distance was $2.0 \mathrm{~cm}$, and intermediate catheter locations were calibrated to marks on the catheter at the proximal end. By varying the radius of curvature and its location, variable distances and catheter paths could be attained (fig. 4h). Deployment of a cell delivery catheter without a preset bend resulted in a $20^{\circ}$ angle of exit from the side port (data not shown).

For a branched pattern of delivery, the user first retracts the catheter into the inner guide tube. After closing the side port, the user can remove the catheter entirely from the device to allow exchange to another catheter shape or alternative therapeutic. A delivery catheter can be safely reintroduced into the closed RBD prototype. Through standard manipulations of the outer guide tube within the stereotactic platform, the user then repositions the side port location to a different rotational angle and/ or depth in accord with the surgical plan. The side port is then opened, and the catheter deployed along this new radial trajectory. By repeating this procedure, the user can produce multiple catheter deployments in a tree-like pattern (fig. 4i).

\section{Integrated Catheter-Plunger System Facilitates Precise Volumes of Delivery and Can Eliminate Device Dead Volume}

Integrating the catheter with its own flexible plunger simplified the delivery mechanism and eliminated the 
Fig. 4. Radial catheter deployment. a, b As the user advances the catheter through the catheter lock at the proximal end, the catheter emerges from the side port along a radially-oriented path. c-g Sequential images taken of catheter deployment overlaid upon an image of the actual final deployed position. The tip of the catheter is dyed blue, to allow easier visualization. $\mathbf{h}$ Four examples of the variable distances and catheter paths that can be attained with $\mathrm{RBD}$. The same RBD guide tube assembly was used to deploy four different catheters, each with a unique radius of curvature. The final position of each catheter was photographed and merged into a single image. i Example of multiple catheter deployments branched from a single cannula trajectory. The final position of six catheter deployments, each performed at a different rotational angle and depth, was photographed and merged, demonstrating the resulting tree-like pattern of deployment.

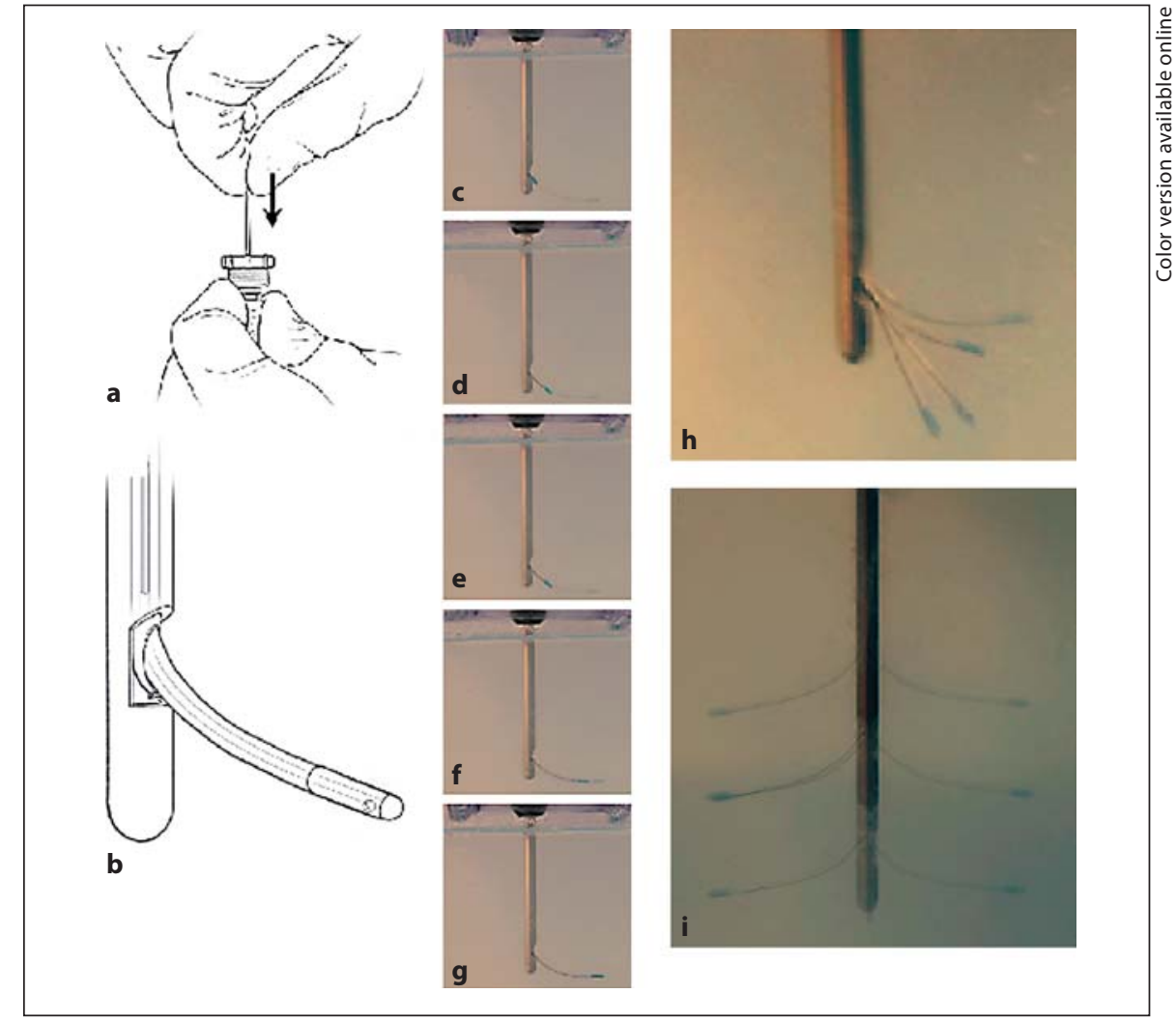

need for a separate syringe. Advancing the plunger within the bore of the catheter allowed the delivery of precise cell volumes through the distal port(s) (fig. 5). The volume delivered was directly proportional to the linear distance of plunger travel $(1.36 \pm 0.13 \mu \mathrm{l}$ per $\mathrm{cm}$ of plunger travel, $\mathrm{n}=50$ trials), and up to $100 \mu \mathrm{l}$ could be delivered with a single catheter. With the catheter in a straight configuration, the dead volume was essentially zero. A catheter with a preset bend has a dead volume related to the proximal location of the curvature, which in the example shown was small $(2.1 \pm 0.36 \mu \mathrm{l})$ relative to the total delivery capacity. In contrast, the $20 \mathrm{G}$ cannula-syringe system exhibited a much larger and variable dead volume (51 $\pm 26 \mu \mathrm{l}, \mathrm{n}=50)$.

\section{NPCs Transit the Catheter-Plunger System with High Viability and Preserved Developmental Potential}

The passage of cells through any device is potentially detrimental to cell viability or biological efficacy. We assessed cell viability before and after passage through both the RBD catheter prototype and the $20 \mathrm{G}$ cannula-syringe system. Single cell suspensions of murine subventricular zone NPCs were prepared at a wide range of cell concen-

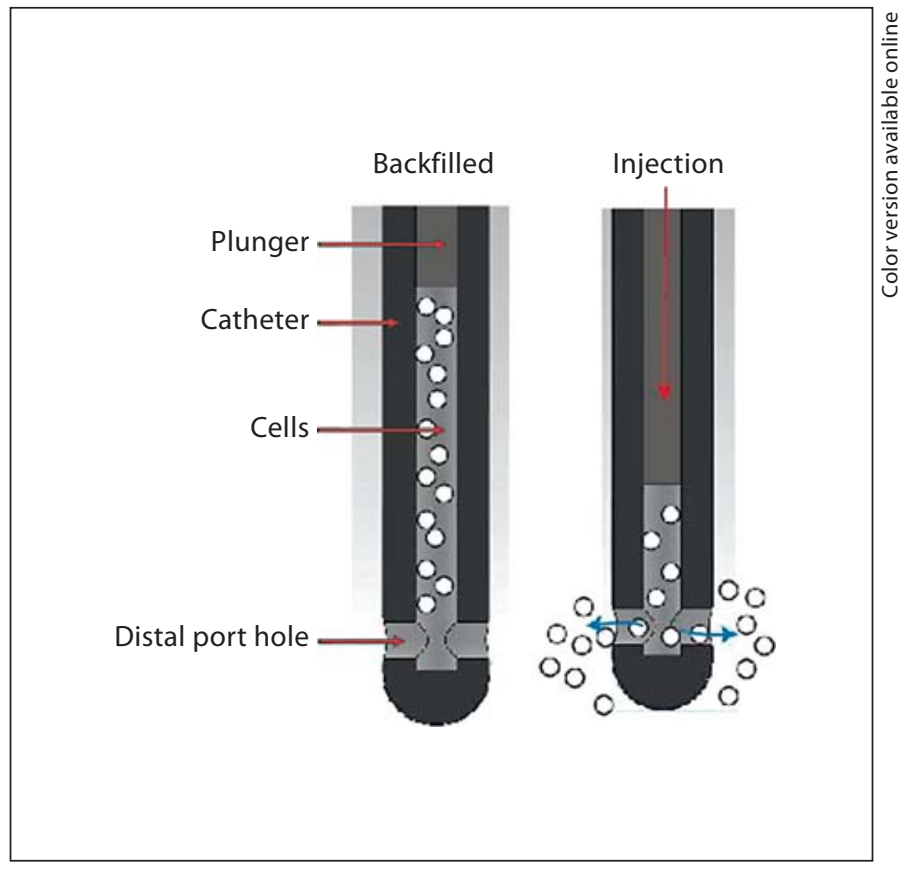

Fig. 5. The integrated catheter-plunger system. Advancing the plunger wire within the bore of the catheter delivers precise volumes of cells through the distal ports. 


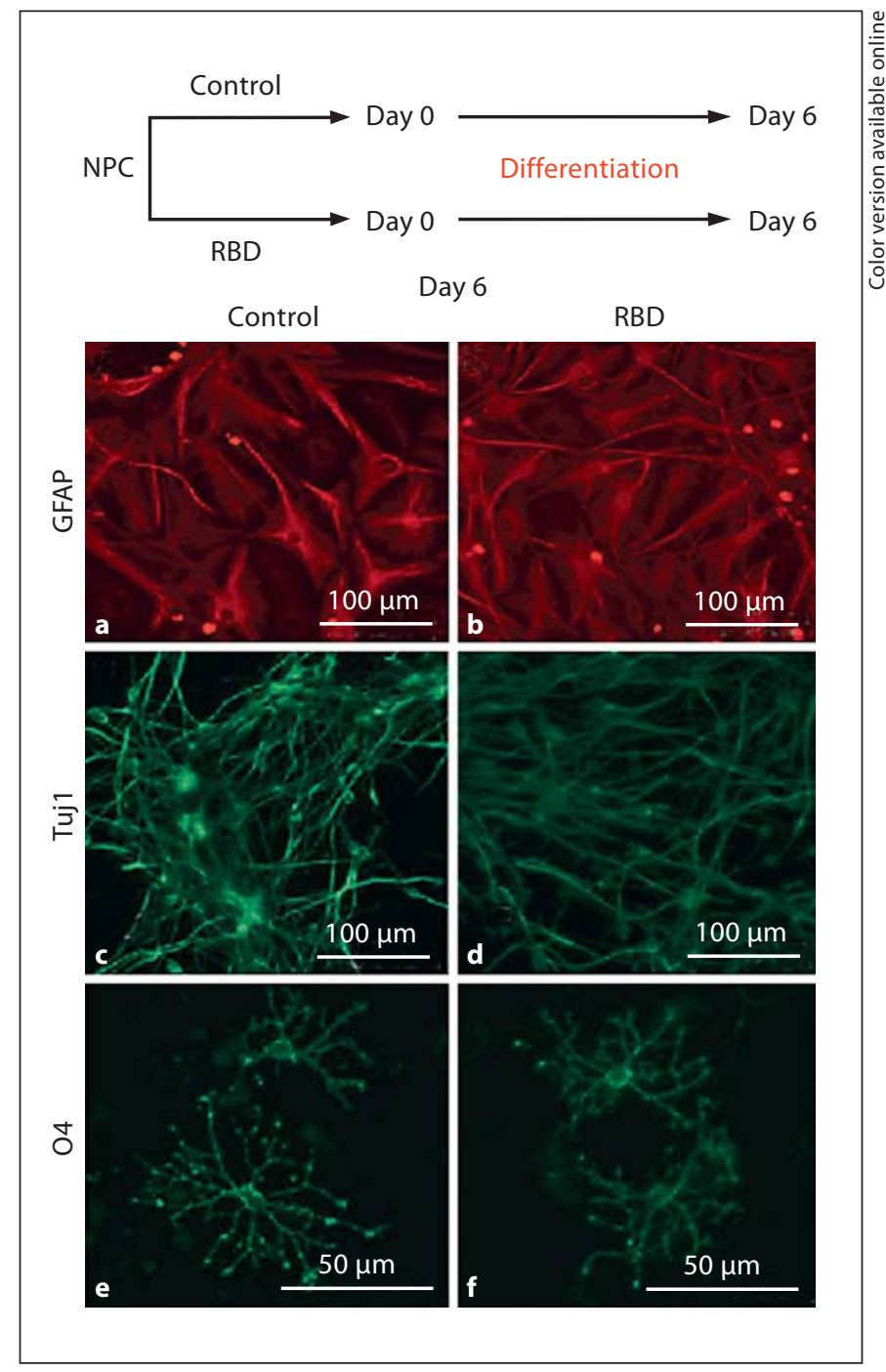

Fig. 6. NPC differentiation after transit through the RBD cell delivery catheter. a, c, e Differentiation of NPCs that did not transit the device (control). $\mathbf{b}, \mathbf{d}, \mathbf{f}$ Differentiation of NPCs that were dispensed through the RBD catheter-plunger system. a, b GFAP (red), astrocyte marker. c, d Tuj1 (green), neuronal marker. e, f O4 (green) oligodendrocyte marker. Colors in the online version only.

trations. After filling the cell delivery catheter, the cell suspensions were manually deployed at a rate of $5 \mu \mathrm{l} / \mathrm{min}$. Cell death was assessed by flow cytometric quantification of Sytox Red uptake (table 1). High viability (>98\%) was observed after transit through both the catheter plunger and 20G cannula-syringe systems. Notably, cells at high density $\left(6 \times 10^{7} \mathrm{cell} / \mathrm{ml}\right)$ were not damaged by transit even at an extremely high rate of delivery $(50 \mu \mathrm{l} /$ min, 99.6\% viability). Furthermore, NPCs recultured af-
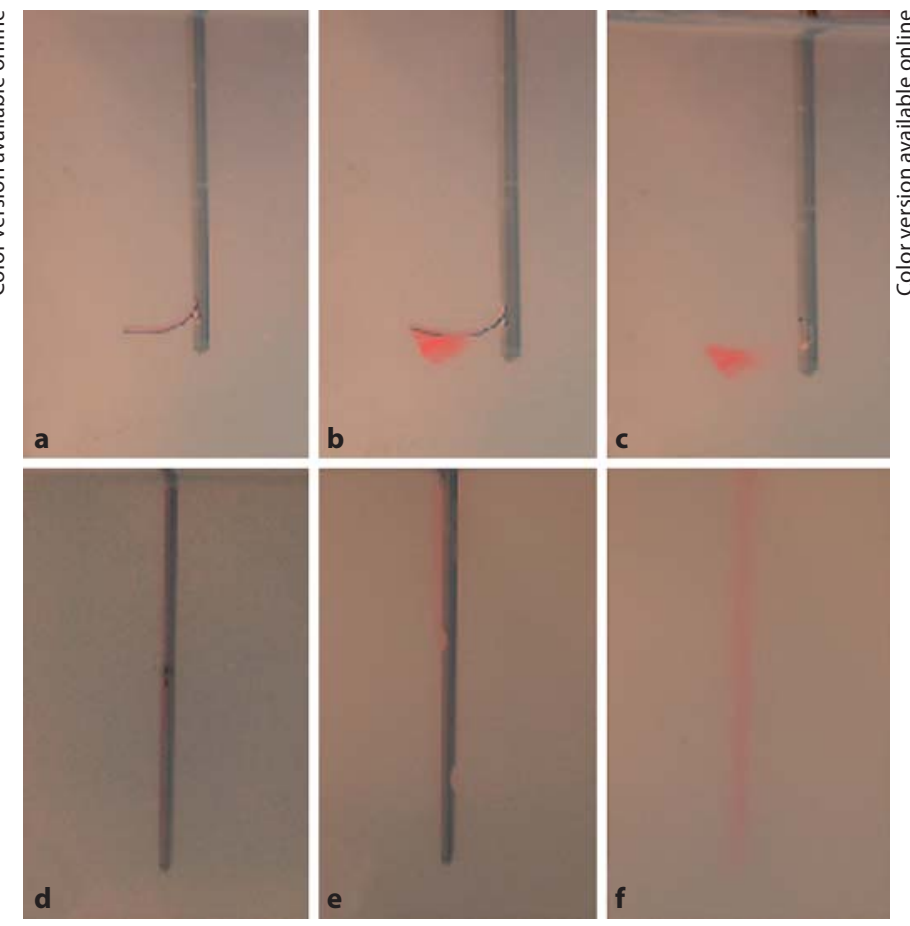

Fig. 7. Evaluation of infusion reflux. Distribution of Allura Red AC dye in agarose gel after delivery through the RBD prototype (a-c) or the 20G cannula-syringe system $(\mathbf{d}-\mathbf{f})$.

ter transit through the RBD catheter could efficiently differentiate into neurons, astrocytes and oligodendrocytes (fig. 6a-f).

\section{Reflux of Cell Suspensions is Minimized with RBD and the Catheter-Plunger System}

The efficient delivery of fluids to solid organs can be hindered by the reflux along the device tract, resulting in loss of therapeutic. We tested for reflux in an agarose gel that mimics the gross structural characteristics of brain tissue [33]. With the RBD prototype, no dye was observed to reflux up the tract created by the outer guide tube (fig. $7 \mathrm{a}-\mathrm{c}$ ). In contrast, delivery of dye through the $20 \mathrm{G}$ cannula-syringe system inserted to the same depth resulted in significant reflux of dye (fig. 7d-f). This difference in reflux was also observed when we used MRI to track the delivery of a suspension of paramagnetic beads to an agarose gel contained within a model skull (data not shown).

To quantify the reflux of cellular suspensions delivered by both the RBD prototype and $20 \mathrm{G}$ cannula-syringe systems, we delivered a suspension of NPCs to the agarose gels. With the RBD prototype, we did not ob- 
Fig. 8. Use of the RBD prototype with the Clearpoint SmartFrame for delivery to the swine brain. a-d Distribution of fluorescent beads after delivery with the RBD prototype. Arrows in (a) and (c) indicate the locations of radial delivery paths, and (b) and (d) show corresponding higherpower fluorescent images of the deposited beads (green). Color in the online version only.
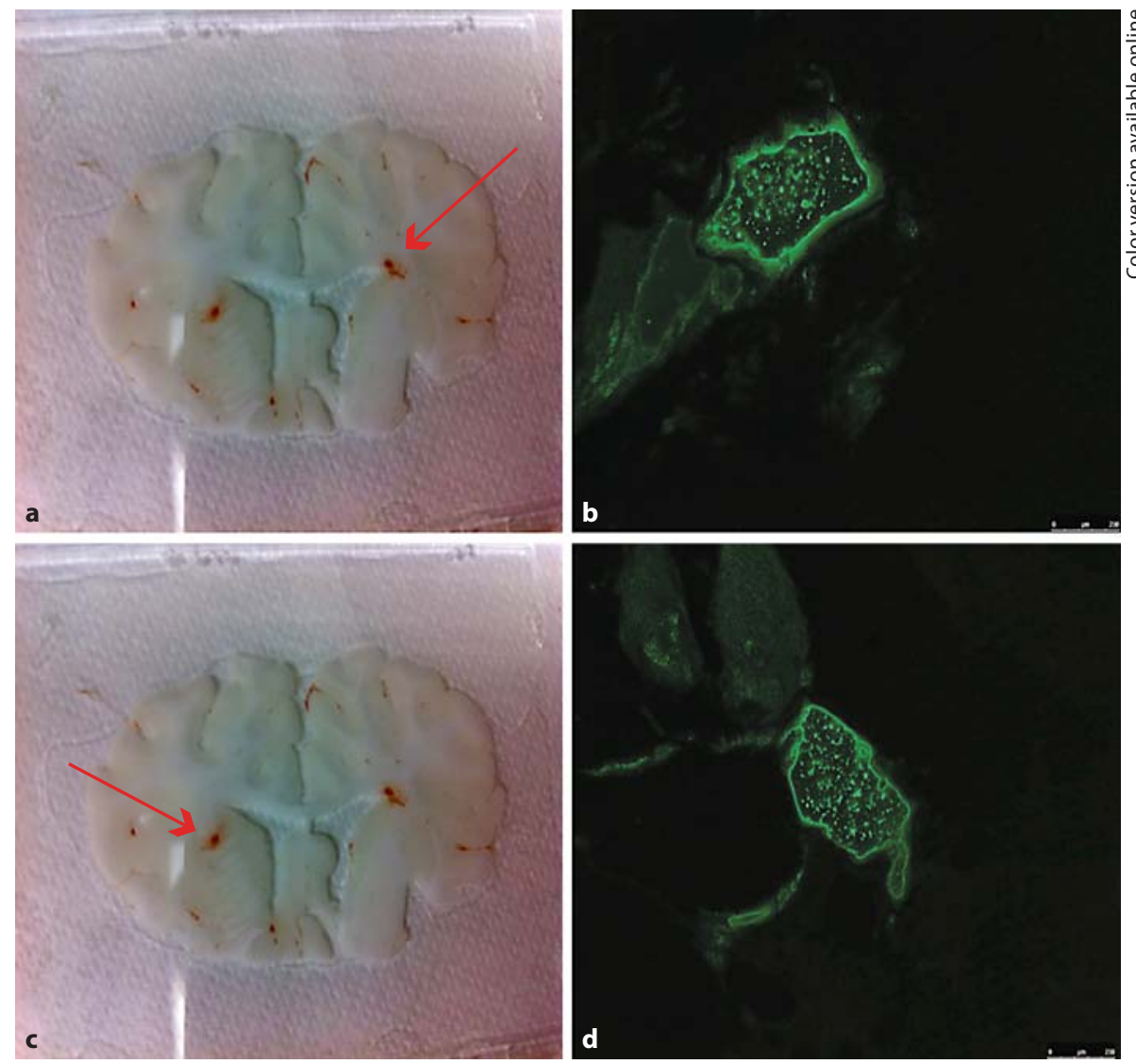

serve any reflux of fluid at the gel surface near the entry point. In contrast, reflux of fluid with the $20 \mathrm{G}$ cannulasyringe system was readily apparent and contained the majority (range $61.5-98.8 \%, \mathrm{n}=4$ ) of the cells dispensed (table 2).

\section{RBD Enables Radial Delivery to the Brain of Swine when Used with a Modern Clinical Stereotactic Platform}

The RBD prototype and surgical strategy is designed as an 'add-on' to standard stereotactic platforms. As cell transplantation would ideally be performed with realtime imaging of the surgical delivery, we chose an MRIcompatible skull-mounted frame to provide evidence of RBD function with currently available stereotactic apparatuses. The RBD prototype was used to deliver a suspension of fluorescent beads along anterior, lateral and posterior radial trajectories in the region of the subcortical white matter. In one animal, we also tested injection with the $20 \mathrm{G}$ cannula system. With the $20 \mathrm{G}$ cannula, reflux was significant, representing at least $75 \%$ of the infusate.
Table 2. Reflux of cells after delivery by the RBD prototype or the $20 \mathrm{G}$ cannula with dual side ports

\begin{tabular}{ccl}
\hline Trial & $\begin{array}{l}\text { Cell density } \\
\text { cells/ml }\end{array}$ & $\begin{array}{l}\text { Alive cells } \\
\%\end{array}$ \\
\hline $\begin{array}{c}\text { Reflux of cells from } \\
20 \text { G cannula }\end{array}$ & \\
1 & $2 \times 10^{6}$ & 61.5 \\
2 & $2 \times 10^{6}$ & 76.9 \\
3 & $5.2 \times 10^{6}$ & 98.8 \\
4 & $5.2 \times 10^{6}$ & 89.3 \\
Reflux of cells from & RBD prototype & \\
1 & $2 \times 10^{6}$ & 0 \\
2 & $2 \times 10^{6}$ & 0 \\
3 & $5.2 \times 10^{6}$ & 0 \\
4 & $5.2 \times 10^{6}$ & 0 \\
\hline
\end{tabular}

In contrast, no reflux and leakage were found with the RBD prototype. Histological analysis of brain sections revealed delivery of beads along the planned radial trajectories (fig. 8a-d), and no intracranial hematomas were observed. 


\section{Discussion}

For cell-based therapies, successful translation of preclinical research into neurosurgical practice requires cell delivery effective at the scale of the human brain. In preclinical animal studies, transplanted cells are usually delivered into the brain with a stereotactically guided straight cannula. To date, cell delivery into the human brain has been performed on hundreds of patients enrolled in clinical trials for the treatment of neurodegenerative disorders using a similar type of straight cannula and syringe. There is a growing recognition that this cell delivery strategy has substantial shortcomings $[18,20$, 24]. RBD provides solutions for several of the limitations that exist with the tools currently being used.

Increased numbers of brain penetrations raises the risk of intracranial hemorrhage, which is the most serious complication observed with procedures of this type [36]. Although the risk for each transcortical penetration is difficult to measure accurately, the incidence of hemorrhage during the placement of deep brain stimulation electrodes through a straight cannula ranges from 0.9 to $12.8 \%$ per implantation [37-39]. Up to half of such procedure-related hematomas result in permanent neurological deficits such as paralysis or cognitive difficulties [37-39]. Furthermore, hematoma-related inflammatory changes may be detrimental to the survival and proper function of transplanted cells. For these reasons, the reduction of transcortical brain penetrations enabled by RBD is important to the overall success of cell transplantation to the brain.

RBD design and strategy are easily compatible with modern stereotactic platforms including the Clearpoint SmartFrame. RBD takes advantage of the ability of computer-aided stereotactic neurosurgical systems to guide a straight, rigid cannula through brain tissue to a selected target with submillimeter accuracy. RBD is designed so that identification of the depth and rotational angle of the side port will determine accurate radial catheter deployment. The precision of RBD catheter deployment allows planning of branched cell deposits based on depth, rotational angle and distance of catheter advancement measured at the proximal end of the RBD guide tube assembly. With modifications to existing planning software, it should be possible to plan complex patterns of delivery to volumetrically large target regions along a single trajectory.

The RBD concept delivers cells through a catheter. However, existing delivery catheters or cannulae are connected to an external syringe via a Luer lock or sim- ilar coupling mechanism $[5,20,26,28]$. This design has several disadvantages: (1) the large disparity in syringe and catheter caliber limits the accuracy and precision of delivery volume without the addition of mechanical or electric devices, (2) shear forces at the transition point between syringe and catheter can damage cells, resulting in reduced viability and (3) cell sedimentation within the syringe can lead to unintended variability of cell dose delivered. The unintended variation in cell dose and viability may confound clinical results by contributing to highly inconsistent patient outcomes, as was observed in trials of fetal dopaminergic neural grafts for PD $[16,17]$.

The incorporation of a wire plunger within the catheter allows the user to dispense infusate volumes with submicroliter accuracy and precision. This may be due to the relatively long translational movements of the plunger wire required to displace small volumes $(1 \mathrm{~cm}$ plunger translation $=1.36 \mu \mathrm{l}$ ). Since the user readily achieves centimeter translational movements, RBD offers precise manual delivery comparable to those obtained with mechanical and electronic assistive devices coupled to a syringe. Currently, we are refining the injection parameters of this catheter-plunger system to optimize cell viability and therapeutic efficacy, which may be a crucial component of clinical trial design, as shown by Kondziolka et al. [25]. Furthermore, the catheter-plunger assembly is readily adaptable for procedures performed in a high-field magnetic environment of intraoperative MRI, as both the catheter and plunger wires are diamagnetic.

Because the RBD strategy allows complete exchange of the catheter-plunger assembly even with the guide tube assembly inserted to the target region, the variability arising from cell sedimentation in a syringe is eliminated. Instead of metering partial injections of the total cell dose, RBD splits the dose into smaller aliquots for each radial trajectory. That is, for each radial catheter deployment, the user dispenses the entire cell dose of the catheter-plunger. With the RBD guide tube side port in the closed position, a depleted catheter-plunger can be safely removed and replaced with another that has been loaded with cells for deployment to another radial location. Because the catheter-plunger subassembly can be filled with different infusate volumes and/or cell concentrations, the user can readily tailor cell dose distribution as needed.

The low elastic modulus (stiffness) of brain tissue provides little resistance to reflux of infusions. Somewhat unexpectedly, the RBD prototype met the practical goal of reducing reflux: reflux was arrested at the transition 
Fig. 9. Schematic illustrating the use of RBD to deliver cells to a larger human brain target. By deploying the catheter at multiple rotational angles and depths, transplantation to larger target regions such as the putamen (pink) can be achieved with a single transcortical brain penetration. Color in the online version only.

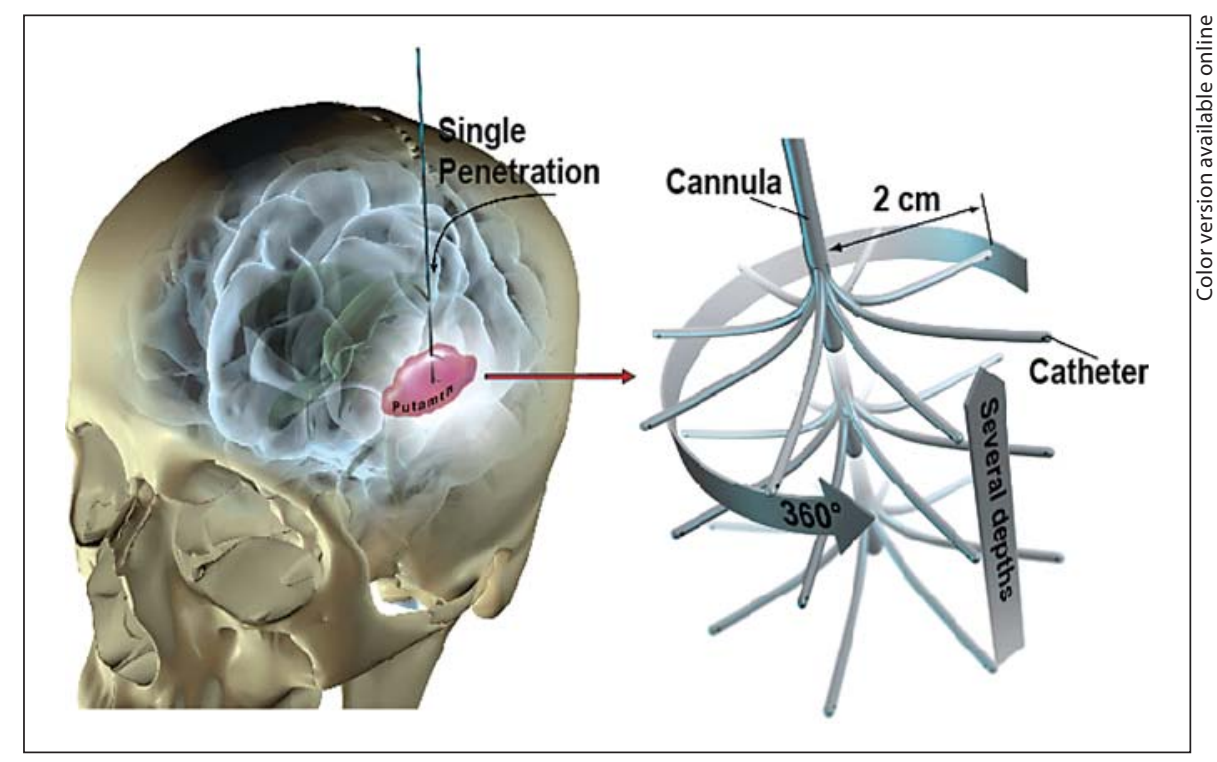

point between the deployed catheter and the outer guide tube side port. This resistance to reflux may be a consequence of the directional change of the tract and the larger caliber of the outer guide tube; similar reflux control has been achieved for a gene therapy delivery cannula, wherein a 'step' on a straight cannula resists reflux at the point of caliber change [40].

Cell transplantation to solid tissues or organs will likely benefit from the ability to deposit multiple cellular grafts throughout the intended target region. In addition to 'common sense' arguments regarding this notion, there are data to support the importance of this strategy. In a study of myoblast transplantation into nonhuman primates, grafts of $1-3 \times 10^{5}$ cells per site did not result in cell death, but transplants of $1 \times 10^{6}, 3 \times 10^{6}, 1 \times 10^{7}$ and $2 \times 10^{7}$ cells resulted in 2, 9, 41 and $59 \%$ of central necrosis, respectively; this cell density-related necrosis was attributed to limitations to the diffusion of oxygen and nutrients through the larger cellular masses $[25,29]$. Also, in the study of cell transplantation to cardiac tissue, multiple small deposits were superior to fewer larger deposits [41].

Cunningham et al. [22] and Bjarkam et al. [24] have also explored the concept of enhancing cell transplantation by using radial trajectories. While their intracerebral microinjection instrument is capable of placing multiple cellular deposits radial to a single proximal brain penetration, the deflection angle achieved is 25 degrees, which limits the radial distance to about $8 \mathrm{~mm}$. Furthermore, this fixed cannula deployment of intracerebral microin- jection instrument limits cell delivery to a conical volume, which complicates targeting. In contrast, the RBD prototype can achieve a deflection angle of 90 degrees with a radial distance of $20 \mathrm{~mm}$. RBD supports interchangeable catheter-plunger assemblies that have preformed radii of curvature, which enable cell transplantation to more complex target volumes. Moreover, RBD, unlike intracerebral microinjection instrument, can be integrated into MR-compatible stereotactic platforms. RBD expands upon the important work of Cunningham et al. [22] by improving cell distribution to more variable target volumes through a single transcortical penetration. Additionally, we are currently exploring the use of RBD as a platform to deliver instrumentation for convection-enhanced delivery.

Our RBD prototype has dimensions similar to that of biopsy needles. Previous studies have shown that cell delivery cannula with dimensions on the same scale as the RBD system can result in long-term survival and engraftment of cells in patients with PD $[5,27,42,43]$; these data suggest that the dimensions of this RBD prototype will be suitable for clinical use. Nonetheless, we are now developing prototypes with reduced dimensions, as there are data suggesting that smaller dimensions reduce gliosis [44]. It will be interesting to see if cell transplantation catheters scaled down to a range of $<100 \mu \mathrm{m}$ can also be effectively deflected to close to 90 degrees, allowing for larger radial distances.

The RBD prototype presented in this study provides a new delivery option for targeted stem cell therapy for PD. 
The putamen (or postcommisural putamen) has been a primary site for dopaminergic cell transplantation in past clinical trials. However, this basal ganglia structure is a difficult target for a straight cannula delivery system as it is both volumetrically large and irregularly shaped (fig. 9). By using T1-weighted, volumetric MRI scans and a stereotactic planning system we have been able to design surgical plans with RBD that can distribute cells to the entire putamen via a single transcortical penetration. By varying depth, rotation, and radial distance components it is possible to deploy the cell delivery catheter throughout the entire putaminal volume $\left(>4 \mathrm{~cm}^{3}\right)$. The basic concept of this RBD strategy is illustrated in fig. 9.

To meet the clinical demands of intraoperative MRIassisted functional neurosurgery, future RBD systems will be comprised entirely of MRI-compatible materials. Such a system, married to modern intraoperative MRIcompatible stereotactic platforms such as the Clearpoint SartFrame, may enhance the accuracy of cell delivery and allow real-time monitoring of cell infusion. Furthermore, by utilizing an existing MRI-compatible platform, cell delivery may one day be performed with the same basic surgical strategy and platform - and perhaps even the same surgical session - as that used for insertion of deep brain stimulation electrodes and gene therapy infusion.

\section{Conclusions}

We present a prototype and surgical method that improves upon previous systems of cell transplantation into the brain. The implementation of RBD may allow more precise delivery of cellular deposits to complex target volumes through a single cortical penetration. Incorporation of RBD or selected aspects of its design into future clinical trials may increase the likelihood of successful translation of cell-based therapy to the human patient.

\section{Acknowledgements}

This work was supported by a grant from the California Institute for Regeneration Medicine (CIRM RT2-01975) and NIH grant DP2-OD006505-01 to D.A.L. In addition, some aspects of this work were supported with resources and the use of facilities at the San Francisco Veterans Affairs Medical Center.

\section{References}

1 Goldman S: Stem and progenitor cell-based therapy of the human central nervous system. Nat Biotechnol 2005;23:862-871.

2 Richardson RM, Barbaro NM, AlvarezBuylla A, Baraban SC: Developing cell transplantation for temporal lobe epilepsy. Neurosurg Focus 2008;24:E17.

3 Lindvall O, Kokaia Z: Stem cells in human neurodegenerative disorders - time for clinical translation? J Clin Invest 2010;120:2940.

4 Aboody K, Capela A, Niazi N, Stern JH, Temple S: Translating stem cell studies to the clinic for CNS repair: current state of the art and the need for a Rosetta stone. Neuron 2011;70:597-613.

5 Freed CR, Greene PE, Breeze RE, Tsai WY, DuMouchel W, Kao R, Dillon S, Winfield H, Culver S, Trojanowski JQ, Eidelberg D, Fahn S: Transplantation of embryonic dopamine neurons for severe Parkinson's disease. New Engl J Med 2001;344:710-719.

-6 Olanow CW, Goetz CG, Kordower JH, Stoessl AJ, Sossi V, Brin MF, Shannon KM, Nauert GM, Perl DP, Godbold J, Freeman TB: A double-blind controlled trial of bilateral fetal nigral transplantation in Parkinson's disease. Ann Neurol 2003;54:403414.
7 Freed CR, Zhou W, Breeze RE: Dopamine cell transplantation for Parkinson's disease: the importance of controlled clinical trials. Neurotherapeutics 2011;8:549-561.

-8 Madrazo I, Franco-Bourland RE, Castrejon $\mathrm{H}$, Cuevas C, Ostrosky-Solis F: Fetal striatal homotransplantation for Huntington's disease: first two case reports. Neurol Res 1995; 17:312-315.

-9 Philpott LM, Kopyov OV, Lee AJ, Jacques S, Duma CM, Caine S, Yang M, Eagle KS: Neuropsychological functioning following fetal striatal transplantation in Huntington's chorea: three case presentations. Cell Transplant 1997;6:203-212.

10 Bachoud-Levi AC, Remy P, Nguyen JP, Brugieres P, Lefaucheur JP, Bourdet C, Baudic S, Gaura V, Maison P, Haddad B, Boisse MF, Grandmougin T, Jeny R, Bartolomeo P, Dalla Barba G, Degos JD, Lisovoski F, Ergis AM, Pailhous E, Cesaro P, Hantraye P, Peschanski M: Motor and cognitive improvements in patients with Huntington's disease after neural transplantation. Lancet 2000;356: 1975-1979.
11 Hauser RA, Furtado S, Cimino CR, Delgado $H$, Eichler S, Schwartz S, Scott D, Nauert GM, Soety E, Sossi V, Holt DA, Sanberg PR, Stoessl AJ, Freeman TB: Bilateral human fetal striatal transplantation in Huntington's disease. Neurology 2002;58:687-695.

12 Benraiss A, Goldman SA: Cellular therapy and induced neuronal replacement for Huntington's disease. Neurotherapeutics 2011;8: 577-590.

13 Kondziolka D, Steinberg GK, Wechsler L, Meltzer CC, Elder E, Gebel J, Decesare S, Jovin T, Zafonte R, Lebowitz J, Flickinger JC, Tong D, Marks MP, Jamieson C, Luu D, BellStephens T, Teraoka J: Neurotransplantation for patients with subcortical motor stroke: a phase 2 randomized trial. J Neurosurg 2005; 103:38-45.

14 Stilley CS, Ryan CM, Kondziolka D, Bender A, DeCesare S, Wechsler L: Changes in cognitive function after neuronal cell transplantation for basal ganglia stroke. Neurology 2004;63:1320-1322.

15 Bliss TM, Andres RH, Steinberg GK: Optimizing the success of cell transplantation therapy for stroke. Neurobiol Dis 2010;37: 275-283.

16 Dunnett SB, Bjorklund A, Lindvall O: Cell therapy in Parkinson's disease - stop or go? Nature reviews 2001;2:365-369. 
17 Lindvall O, Bjorklund A: Cell therapy in Parkinson's disease. NeuroRx 2004;1:382-393.

18 Brecknell JE, Fawcett JW: A device for the implantation of multiple cellular deposits into a large volume of brain from a single cannula site. Exp Neurol 1996;138:338-344.

$\checkmark 19$ Bankiewicz KS, Bringas J, Pivirotto P, Kutzscher E, Nagy D, Emborg ME: Technique for bilateral intracranial implantation of cells in monkeys using an automated delivery system. Cell Transplant 2000;9:595607.

20 Mendez I, Hong M, Smith S, Dagher A, Desrosiers J: Neural transplantation cannula and microinjector system: experimental and clinical experience. Technical note. J Neurosurg 2000;92:493-499.

-21 Kondziolka D, Steinberg GK, Cullen SB, McGrogan M: Evaluation of surgical techniques for neuronal cell transplantation used in patients with stroke. Cell Transplant 2004;13: 749-754.

-22 Cunningham MG, Bolay H, Scouten CW, Moore C, Jacoby D, Moskowitz M, Sorensen JC: Preclinical evaluation of a novel intracerebral microinjection instrument permitting electrophysiologically guided delivery of therapeutics. Neurosurgery 2004;54: 1497-1507, discussion p 1507.

-23 Gobbel GT, Kondziolka D, Fellows-Mayle W, Uram M: Manual vs automated delivery of cells for transplantation: accuracy, reproducibility, and impact on viability. Neurosurgery 2010;67:1662-1668; discussion $p$ 1668.

-24 Bjarkam CR, Glud AN, Margolin L, Reinhart K, Franklin R, Deding D, Ettrup KS, Fitting LM, Nielsen MS, Sorensen JC, Cunningham MG: Safety and function of a new clinical intracerebral microinjection instrument for stem cells and therapeutics examined in the Göttingen minipig. Stereotact Funct Neurosurg 2010;88:56-63.

-25 Kondziolka D, Gobbel G, Fellows-Mayle W, Chang YF, Uram M: Injection parameters affect cell viability and implant volumes in automated cell delivery for the brain. Cell Transplant 2011;20:1901-1906.
26 Breeze RE, Wells TH, Jr., Freed CR: Implantation of fetal tissue for the management of Parkinson's disease: a technical note. Neurosurgery 1995;36:1044-1047; discussion pp 1047-1048.

27 Mendez I, Sanchez-Pernaute R, Cooper O, Vinuela A, Ferrari D, Bjorklund L, Dagher A, Isacson $\mathrm{O}$ : Cell type analysis of functional fetal dopamine cell suspension transplants in the striatum and substantia nigra of patients with Parkinson's disease. Brain 2005; 128:1498-1510.

28 Selden NR, Guillaume DJ, Huhn S, Koch TK, Steinder RD: CNS Transplantation of Purified Neural Stem Cells in Neuronal Ceroid Lipofuscinoses: Phase I Trial. Philidelphia, American Association of Neurological Surgeons, 2010.

29 Skuk D, Paradis M, Goulet M, Tremblay JP: Ischemic central necrosis in pockets of transplanted myoblasts in nonhuman primates: implications for cell-transplantation strategies. Transplantation 2007;84:1307-1315.

30 Valles F, Fiandaca MS, Bringas J, Dickinson P, LeCouteur R, Higgins R, Berger M, Forsayeth J, Bankiewicz KS: Anatomic compression caused by high-volume convection-enhanced delivery to the brain. Neurosurgery 2009;65:579-585, discussion pp 585-576.

31 Yin D, Valles FE, Fiandaca MS, Bringas J, Gimenez F, Berger MS, Forsayeth J, Bankiewicz KS: Optimal region of the putamen for image-guided convection-enhanced delivery of therapeutics in human and non-human primates. Neuroimage 2011;54(suppl 1):S196-S203.

32 Kondziolka D: Device for cell delivery into the brain or body; in Office UPaT (ed). USA, 2008, application.

33 Pervin F, Chen WW: Mechanistically similar gel simulants for brain tissues; in Proulx T (ed): Dynamic Behavior of Materials. New York, Springer, 2011, vol 1, pp 9-13.

34 Scheffler B, Walton NM, Lin DD, Goetz AK, Enikolopov G, Roper SN, Steindler DA: Phenotypic and functional characterization of adult brain neuropoiesis. Proc Natl Acad Sci USA 2005; 102:9353-9358.

35 Lim DA, Huang YC, Swigut T, Mirick AL, Garcia-Verdugo JM, Wysocka J, Ernst P, Alvarez-Buylla A: Chromatin remodelling factor Mll1 is essential for neurogenesis from postnatal neural stem cells. Nature 2009; 458:529-533.
36 Deep-Brain Stimulation for Parkinson's Disease Study Group. Deep-brain stimulation of the subthalamic nucleus or the pars interna of the globus pallidus in Parkinson's disease. New Engl J Med 2001;345:956-963.

37 Binder DK, Rau G, Starr PA: Hemorrhagic complications of microelectrode-guided deep brain stimulation. Stereotact Funct Neurosurg 2003;80:28-31.

38 Binder DK, Rau GM, Starr PA: Risk factors for hemorrhage during microelectrodeguided deep brain stimulator implantation for movement disorders. Neurosurgery 2005; 56:722-732, discussion pp 722-732.

39 Zrinzo L, Foltynie T, Limousin P, Hariz MI: Reducing hemorrhagic complications in functional neurosurgery: a large case series and systematic literature review. J Neurosurg 2012;116:84-94.

40 Krauze MT, Saito R, Noble C, Tamas M, Bringas J, Park JW, Berger MS, Bankiewicz $\mathrm{K}$ : Reflux-free cannula for convection-enhanced high-speed delivery of therapeutic agents. J Neurosurg 2005;103:923-929.

41 Ott HC, Kroess R, Bonaros N, Marksteiner R, Margreiter E, Schachner T, Laufer G, Hering S: Intramyocardial microdepot injection increases the efficacy of skeletal myoblast transplantation. Eur J Cardiothorac Surg 2005;27:1017-1021.

42 Li JY, Englund E, Holton JL, Soulet D, Hagell P, Lees AJ, Lashley T, Quinn NP, Rehncrona $\mathrm{S}$, Bjorklund A, Widner $\mathrm{H}$, Revesz T, Lindvall $\mathrm{O}$, Brundin P: Lewy bodies in grafted neurons in subjects with Parkinson's disease suggest host-to-graft disease propagation. Nat Med 2008; 14:501-503.

43 Kordower JH, Chu Y, Hauser RA, Freeman TB, Olanow CW: Lewy body-like pathology in long-term embryonic nigral transplants in Parkinson's disease. Nat Med 2008;14:504506.

44 Nikkhah G, Olsson M, Eberhard J, Bentlage C, Cunningham MG, Bjorklund A: A microtransplantation approach for cell suspension grafting in the rat Parkinson model: a detailed account of the methodology. Neuroscience 1994;63:57-72. 